\title{
PENERAPAN OCCUPATIONAL HEALTH AND SAFETY ASSESSMENT SERIES : 18001 DI PT. DOK DAN PERKAPALAN SURABAYA (PERSERO) TAHUN 2017
}

\author{
Ach Romadhon, Demes Nurmayanti, Imam Khambali
}

\begin{abstract}
ABSTRAK
Kecelakaan kerja dapat menimbulkan berbagai macam kerugian. Di samping dapat mengakibatkan korban jiwa, juga dapat menyebabkan kerugian waktu kerja (pemberhentian sementara), penurunan produktivitas, pengaruh psikologis yang negative pada pekerja, memburuknya reputasi perusahaan, denda dari pemerintah, serta kemungkinan berkurangnya kesempatan usaha atau kehilangan pelanggan pengguna jasa. Dari data riwayat kecelakaan kerja di PT. Dok dan Perkapalan Surabaya pada tahun 2010 terjadi 7 kasus kecelakaan kerja, tahun 2011 terjadi 15 kasus kecelakaan kerja, tahun 2012 terjadi 9 kasus kecelakaan kerja, tahun 2013 terjadi 4 kasus kecelakaan kerja, tahun 2014 terjadi 2 kasuskecelakaan kerja, tahun 2015 terjadi 5 kasus kecelakaan dan tahun 2016 terjadi 3 kasus kecelakaan kerja. Tujuannya mengetahui penerapan OHSAS 18001 di PT. Dok dan Perkapalan Surabaya (Persero).

Jenis penelitian ini adalah deskriptif dengan pendekatan kualitatif. Teknik sampling yang digunakan adalah proporsional random sampling dengan jumlah sampel sebanyak 73 orang tenaga kerja dari bagian produksi. Jenis pengumpulan data yang digunakan adalah wawancara, observasi dan studi dokumentasi. Data dianalisis dalam bentuk tabel.

Hasil penilaian didapatkan nilai sebesar 93\% untuk komponen kebijakan K3, 95\% untuk komponen perencanaan $\mathrm{K} 3,90 \%$ untuk komponen penerapan $\mathrm{K} 3,93 \%$ untuk komponen evaluasi K3, dan $97 \%$ untuk komponen tindakan perbaikan. Seluruh penilaian yang didapatkan dikategorikan dalam kriteria baik, sehingga jumlah angka kecelakaan kerja di PT. Dok dan Perkapalan Surabaya (Persero) menurun.

Disarankan perusahaan harus melaksanakan komitmen pengawasan sehingga SMK3 di PT. Dok dan Perkapalan Surabaya (Persero) dapat berjalan dengan baik dan dapat mengurangi angka kecelakaan kerja.
\end{abstract}

Kata Kunci : OHSAS 18001, Keselamatan dan Kesehatan Kerja

\section{PENDAHULUAN}

Produktivitas kerja merupakan istilah yang sering digunakan dalam perencanaan pengembangan industri pada khususnya dan perencanaan pengembangan ekonomi sosial pada umumnya yang sesuai dengan manajemen perusahaan tersebut. Manajemen sebagai salah satu ilmu perilaku yang mencakup aspek sosial tidak terlepas dari tanggung jawab kesehatan dan keselamatan kerja, baik dari perencanaan, maupun pengambilan keputusan dan organisasi. Manajemen yang baik dapat mengurangi angka kecelakaan kerja (Sastrohadiwiryo, 2003).

Keselamatan dan kesehatan kerja $m$ erupakan hal yang sangat penting bagi perusahaan, karena dampak kecelakaan dan penyakit akibat kerja tidak hanya merugikan karyawan, tetapi juga perusahaan baik secara langsung maupun tidak langsung (Achmad Ramadhan, 2012).

OHSAS (Occupational Health And Safety Assessment Series) adalah standar internasional untuk penerapan sistem manajemen kesehatan dan keselamatan kerja yang mempunyai tujuan melindungi para pekerja dari hal yang tidak diinginkan yang timbul dari lingkungan kerja yang berdampak pada kesehatan dan keselamatan kerja dan tidak menimbulkan kerugian bagi perusahaan serta pekerja itu sendiri, sedangkan SMK3 merupakan konsep pengelolaan K3 secara sistematis dan komprehensif dalam suatu sistem manajemen yang utuh melalui proses perencanaan, penerapan, pengukuran, dan pengawasan. (Ramli, 2010)

PT. Dok dan Perkapalan Surabaya (Persero) sebagai salah satu industri reparasi kapal memiliki kemungkinan 
terjadinya kecelakaan kerja dalam pelaksanaan produksi maupun aktivitas perusahaan. Terdapat data riwayat kecelakaan kerja yang masih naik turun dari tahun 2010 sampai 2016. Pada tahun 2010 terjadi 7 kasus kecelakaan kerja, tahun 2011 terjadi 15 kasus kecelakaan kerja, tahun 2012 terjadi 9 kasus kecelakaan kerja, tahun 2013 terjadi 4 kasus kecelakaan kerja, tahun 2014 terjadi 2 kasus kecelakaan kerja, tahun 2015 terjadi 5 kasus kecelakaan dan tahun 2016 terjadi 3 kasus. Kecelakaan kerja di PT. Dok dan Perkapalan Surabaya (Persero) itu terdiri dari kecelakaan ringan, sedang dan berat. Pada tahun 2015 terjadi kecelakaan yang menimbulkan kematian sebanyak 1 kasus. Berdasarkan latar belakang permasalahan tersebut, penelitian ini bertujuan untuk mengetahui penerapan OHSAS 18001 di PT. Dok dan Perkapalan Surabaya (Persero) dalam mengurangi kecelakaan kerja.

\section{METODE PENELITIAN}

Jenis penelitian ini termasuk deskriptif yang menggambarkan SMK3 yang diterapkan di PT. Dok dan Perkapalan Surabaya (Persero). Populasi dalam penelitian ini adalah seluruh tenaga kerja di bagian produksi, dengan jumlah sampel sebanyak 73 orang. Metode yang digunakan dalam pengumpulan data adalah wawancara, lembar observasi dan studi dokumentasi tentang SMK3 yang diiliki PT. Dok dan perkapalan Surabaya (Persero). Data dianalisis dalam bentuk tabel.

\section{HASIL DAN PEMBAHASAN Kebijakan K3}

Kebijakan K3 merupakan perwujudan dari komitmen pucuk pimpinan yang memuat visi dan tujuan organisasi, komitmen dan tekad untuk melaksanakan keselamatan dan kesehatan kerja, kerangka dan program kerja.

Tabel 1

HASIL PENILAIAN KEBIJAKAN K3 DI PERUSAHAAN

\begin{tabular}{clc}
\hline NO & \multicolumn{1}{c}{ KOMPONEN PENILAIAN } & HASIL (\%) \\
\hline 1 & Adanya organisasi K3 & 100 \\
\hline 2 & Divisi K3 digunakan untuk menentukan keputusan & 67 \\
\hline 3 & Ada visi dan tujuan & 100 \\
\hline 4 & $\begin{array}{l}\text { Adanya kebijakan K3 dari pimpinan dan di } \\
\text { tandatangani oleh pimpinan }\end{array}$ & 100 \\
\hline 5 & Kebijakan di dokumentasikan ditinjau secara berkala & 100 \\
\hline 6 & Ada SOP tentang K3 & 100 \\
\hline 7 & Kebijakan dikonsultasikan kepada karyawan & 100 \\
\hline 8 & Kebijakan dikomunikasikan kepada karyawan & 100 \\
\hline 9 & Pimpinan aktif dalam kegiatan K3 & 67 \\
\hline 10 & Petugas K3 memahami UU K3 & 100 \\
\hline \multicolumn{2}{c}{ Rata-rata } & 93 \\
\hline
\end{tabular}

Berdasarkan hasil wawancara petugas K3 sebanyak 2 responden menyatakan telah menempatkan seorang ahli K3 untuk menetukan keputusan, dan 1 responden menyatakan belum menempatkan seorang ahli K3 untuk menetukan keputusan.

Peneliti menganalisis bahwa responden yang menjawab tidak pada indikator ini disebabkan karena kurangnya pengawasan dari pihak perusahaan, belum adanya campur tangan dari pihak manajemen terkait pengambilan keputusan jika terjadi kecelakaan kerja.
Hal ini disebabkan karena sifat pekerjaan yang dinamis sehingga dalam proses pekerjaan sangat tinggi terutama bagi para pekerja di lapangan, serta kurangnya koordinasi antara pimpinan dengan karyawan (Alfred Billy Wuon, 2013).

Penilaian pada 2 responden menyatakan pimpinan aktif dalam kegiatan K3, dan sebanyak 1 responden menyatakan pimpinan tidak aktif dalam kegiatan K3. Peneliti menganalisis bahwa responden yang menjawab tidak pada indikator ini disebabkan oleh kurangnya 
koordinasi antara pimpinan dengan karyawan. Upaya yang harus dilakukan pada indikator ini yaitu manajer serta seluruh manajemen K3 dan manajemen lini lainya, harus mempunyai tanggung jawab yang pasti dalam melakukan identifikasi semua perundangan, peraturan atau standar yang berlaku dan pemutakhiran peraturan perundangan yang digunakan organisasi. Sehingga, konsep ini dapat menciptakan lingkungan kerja yang aman, sehat, dan efisien (Sahab MS, 1997).

\section{Perencanaan K3}

Perencanaan K3 yang baik dimulai dengan melakukan identifikasi bahaya, penilaian risiko dan penentuan pengendalianya.

Tabel 2

HASIL PENILAIAN PERENCANAAN K3 DI PERUSAHAAN

\begin{tabular}{|c|c|c|}
\hline NO & KOMPONEN PENILAIAN & HASIL (\%) \\
\hline 1 & Terdapat kebijakan untuk K3 & 100 \\
\hline 2 & Ada sanksi jika terjadi pelanggaran & 67 \\
\hline 3 & Terdapat IBPR di setiap proses kerja & 100 \\
\hline 4 & Tersedianya anggaran untuk K3 & 100 \\
\hline 5 & Tersedianya anggaran memadai untuk SDM & 100 \\
\hline 6 & Terdapat rencana program kerja & 100 \\
\hline \multirow[t]{2}{*}{7} & Tersedia APD & 100 \\
\hline & Rata-rata & 95 \\
\hline
\end{tabular}

Berdasarkan hasil wawancara Petugas K3L sebanyak 2 responden menyatakan bahwa ada sanksi yang tegas dari pihak perusahaan jika terjadi pelanggaran. Seorang responden menyatakan bahwa tidak ada sanksi yang tegas jika terjadi pelanggaran. Peneliti menganalisis bahwa responden yang menjawab tidak pada indikator ini disebabkan karena masih banyak karyawan subkon yang tidak memakai APD sesuai dengan kondisi pekerjaan, merokok di area kerja pada saat bekerja. Pihak perusahaan diketahui tidak tegas dalam memberikan sanksi pada karyawan yang melanggar aturan yang telah ditetapkan. Sanksi yang diterapkan berupa teguran tanpa adanya tindak lajut jika karyawan tersebut mengulangi kesalahan yang sama, misalnya dikeluarkan.
Upaya yang harus dilakukan pada indikator ini yaitu manajer serta seluruh manajemen K3 dan manajemen lini lainya, harus mempunyai tanggungjawab yang pasti dalam melakukan identifikasi semua perundangan, peraturan atau standar yang berlaku dan pemutakhiran peraturan perundangan yang digunakan organisasi. Sehingga, melalui konsep ini dapat menciptakan lingkungan kerja yang aman, sehat, dan efisien (Silaban, 2009).

\section{Penerapan K3}

Penerapan yang baik didukung oleh top manajemen yang memegang tanggung jawab tertinggi, pelaksanaan program K3 dan SMK3, komitmen top manajemen tersebut terwujud dalam bentuk memastikan tersedianya sumber daya yang meliputi, strukur organisasi dan teknologi. 
Tabel 3

HASIL PENILAIAN PENERAPAN K3 DI PERUSAHAAN

\begin{tabular}{clc}
\hline NO & \multicolumn{1}{c}{ KOMPONEN PENILAIAN } & HASIL (\%) \\
\hline 1 & Tujuan dan prioritas SMK3 diutamakan & 100 \\
\hline 2 & Memiliki organisasi P2K3 & 45 \\
\hline 3 & Adanya pelatihan K3 & 100 \\
\hline 4 & Adanya sosialisasi mengenai K3 & 100 \\
\hline 5 & Kualitas APD sesuai standart & 100 \\
\hline 6 & Perusahaan bertanggung atas kinerja K3 & 100 \\
\hline 7 & Perusahaan menjaga peralatan/mesin sehinga aman & 90 \\
\hline 8 & $\begin{array}{l}\text { Terdapat prosedur pemantauan dan tanggung jawab } \\
\text { K3 }\end{array}$ & 100 \\
\hline 9 & $\begin{array}{l}\text { Perusahaan selalu menjaga kondisi tempat kerja } \\
\text { sehat }\end{array}$ & 73 \\
\hline & \multicolumn{2}{c}{ Rata-rata } \\
\hline
\end{tabular}

Berdasarkan hasil wawancara kepada 73 karyawan dan petugas K3L, sebanyak 33 responden menyatakan bahwa PT. Dok dan Perkapalan Surabaya memiliki panitia pembina keselamatan dan kesehatan kerja (P2K3), namun sebanyak 40 responden belum mengetahui adanya panitia pembina keselamatan dan kesehatan kerja (P2K3). Peneliti menganalisis responden yang menjawab tidak disebabkan karena kurangnya pengenalan P2K3 dan organisasi tidak berjalan dengan aktif. Berdasarkan PP no. 50 tahun 2012 Perusahaan wajib membentuk P2K3 yang betanggung jawab dibidang K3. P2K3 mempunyai tugas memberikan saran dan pertimbangan baik diminta maupun tidak kepada pengusaha atau pengurus mengenai masalah kesalamatan dan kesehatan kerja.

Sebanyak 66 responden mengatakan perusahaan menjaga peralatan/mesin sehingga aman (PP No. 50 tahun 2012). Namun masih terdapat 7 responden yang menyatakan bahwa perusahaan tidak menjaga peralatan/mesin sehingga tidak aman.

Peneliti menganalisis bahwa responden yang menjawab tidak disebabkan karena masih ditemukanya peralatan/mesin yang kurang berfungsi dengan baik, meskipun inspeksi yang dilakukan rutin yaitu inspeksi harian dan mingguan.

Pada indikator perusahaan selalu menjaga kondisi tempat agar tetap sehat, sebanyak 53 responden menyatakan bahwa perusahaan sudah memenuhi indikator tersebut, namun sebanyak 20 responden mengatakan bahwa perusahaan tidak menjaga tempat kerjanya. Peneliti menganalisis bahwa responden yang menjawab tidak disebabkan oleh kurangnya sosialisasi mengenai K3 sehingga masih ada karyawan yang belum mengetahui bahwa PT. Dok dan Perkapalan Surabaya sudah menjaga tempat kerjanya agar tetap sehat.

Upaya yang dilakukan untuk menjaga kondisi tempat kerja agar tetap sehat, dilakukan melalui kegiatan pembersihan kantor setiap minggu. Upaya pembersihan tersebut tidak hanya dilakukan di kantor tetapi juga di lokasi proyek seperti membersihkan kotoran bekas galian di jalan. Hal ini, ditujukan tidak hanya untuk kenyamanan para pekerja di lapangan tetapi juga kenyamanan masyarakat pengguna jalan (Achmad Ramadhan, 2012).

\section{Evaluasi K3}

Sistem pengukuran terhadap pelaksanaan SMK3 Konsisten dengan komitmen untuk melaksanakan kebijakan keselamatan disuatu perusahaan dengan membangun, mengimplementasikan dan melakukan perawatan prosedur secara periodik serta evaluasi yang disesuaikan dengan peraturan yang ada dan membandingkan dengan peraturan yang lainnya. 
Tabel 4

HASIL PENILAIAN EVALUASI K3 DI PERUSAHAAN

\begin{tabular}{clc}
\hline NO & \multicolumn{1}{c}{ KOMPONEN PENILAIAN } & HASIL (\%) \\
\hline 1 & Terdapat tanda peringatan di tempat berbahaya & 100 \\
\hline 2 & Terdapat penyelidikan dari insiden kecelakaan & 73 \\
\hline 3 & $\begin{array}{l}\text { Terdapat audit internal yang dilakukan oleh orang } \\
\text { yang mempunyai sertifikat dan memiliki potensi di } \\
\text { bidang audit }\end{array}$ & 100 \\
\hline 4 & $\begin{array}{l}\text { Melakukan tinjauan ulang penerapan SMK3 secara } \\
\text { efektif }\end{array}$ & 100 \\
\hline \multicolumn{1}{c}{ Rata-rata } & 93 \\
\hline
\end{tabular}

Berdasarkan hasil wawancara sebanyak 73 karyawan dan petugas K3L, sebanyak 53 responden menyatakan perusahaan telah melakukan penyelidikan insiden kecelakaan, sebanyak 20 responden menyatakan bahwa PT. Dok dan Perkapalan Surabaya (Persero) belum melakukan penyelidikan insiden kecelakaan. Peneliti menganalisis responden yang menjawab tidak disebabkan karena kurangnya koordinasi pimpinan dengan karyawan dalam melakukan penyelidikan jika terjadi kecelakaan.

Penyelidikan terhadap kecelakaan kerja harus dilaksanakan segera mungkin setelah kecelakaan untuk memastikan bahwa kondisi saat kecelakaan belum banyak berubah. Selain itu, untuk memudahkan prosedur pelaksanaan penyelidikan maka perusahaan juga memiliki SOP mengenai pelaksananaan penyelidikan kecelakaan kerja (Robert L Mathis \& John H Jackson, 2002).

\section{Tindakan Perbaikan}

Top managemen harus mereview sistem organisasi SMK3, jarak pelaksanaan audit yang telah direncanakan untuk meyakinkan adanya kesesuaian yang berkelanjutan dan keefektifitasan.

Tabel 5

HASIL PENILAIAN TINDAKAN PERBAIKAN DI PERUSAHAAN

\begin{tabular}{clc}
\hline NO & \multicolumn{1}{c}{ KOMPONEN PENILAIAN } & HASIL (\%) \\
\hline 1 & $\begin{array}{l}\text { Terdapat tindakan perbaikan terhadap alat } \\
\text { pekerjaan }\end{array}$ & 100 \\
\hline 2 & Terdapat inspeksi ke lapangan & 92 \\
\hline 3 & Dilakukan tindakan perbaikan sesuai kebijakan K3 & 100 \\
\hline \multicolumn{2}{c}{ Rata-rata } & 97 \\
\hline
\end{tabular}

Berdasarkan hasil wawancara sebanyak 73 karyawan dan petugas K3L, sebanyak 67 responden menyatakan bahwa di PT. Dok dan Perkapalan Surabaya sudah melakukan inspeksi ke lapangan. Inspeksi yang dilakukan berupa Safety Patrol. Kegiatan ini dilaksanakan untuk mencegah terjadinya kecelakaan akibat kecerobohan pekerja maupun kondisi lingkungan yang berbahaya. Sebanyak 6 responden menyatakan PT. Dok dan Perkapalan Surabaya belum melakukan inspeksi ke lapangan. Peneliti menganalisis responden yang menjawab tidak disebabkan karena kurangnya pengetahuan karyawan.

Perusahaan telah melakukan pemantauan dan pengukuran lingkungan kerja secara teratur dan hasilnya didokumentasikan, dipelihara dan digunakan untuk penilaian dan pengendalian risiko (PP. No 50 tahun 2012).

\section{Angka Kecelakaan Kerja}

Berikut adalah hasil perhitungan angka kecelakaan kerja berdasarkan frequency rate dan severity rate. 
Tabel 6

HASIL PERHITUNGAN ANGKA KECELAKAAN KERJA

\begin{tabular}{ccccccccc}
\hline NO & JENIS & \multicolumn{7}{c}{ TAHUN } \\
\cline { 3 - 10 } & PEMERIKSAAN & $\mathbf{2 0 1 0}$ & $\mathbf{2 0 1 1}$ & $\mathbf{2 0 1 2}$ & $\mathbf{2 0 1 3}$ & $\mathbf{2 0 1 4}$ & $\mathbf{2 0 1 5}$ & $\mathbf{2 0 1 6}$ \\
\hline 1 & Frequency rate & 3 & 7 & 4 & 2 & 1 & 2 & 1 \\
\hline 2 & Severity rate & 24 & 52 & 31 & 13 & 7 & 17 & 10 \\
\hline
\end{tabular}

Berdasarkan hasil perhitungan angka rata-rata kecelakaan kerja selama 7 tahun terakhir besar frequency rate sebanyak 2.85, sedangkan rata-rata jumlah hari hilang selama 7 tahun terakhir berdasarkan Severity rate sebanyak 22 hari hilang pekerjaan. Angka kecelakaan kerja di PT. Dok dan Perkapalan Surabaya (Persero) termasuk kategori kecil, hal ini dikarenakan adanya kebijakan K3, perencanaan $\mathrm{K} 3$, penerapan $\mathrm{K} 3$, evaluasi K3, dan tindakan perbaikan SMK3 perusahaan dalam penilaian berjalan dengan baik.

\section{KESIMPULAN}

1. Kebijakan K3 didapatkan penilaian sebesar 93\% sehingga dikategorikan baik dan telah menerapkan kebijakan K3 sesuai dengan ketentuan PP No. 50 tahun 2012.

2. Pada komponen perencanaan K3 didapatkan penilaian sebesar 95\% sehingga dikategorikan baik dan telah menerapkan perencanaan K3 sesuai dengan ketentuan PP No. 50 tahun 2012.

3. Pada komponen penerapan K3 didapatkan penilaian sebesar 90\% sehingga dikategorikan baik dan telah menerapkan K3 sesuai dengan ketentuan PP No. 50 tahun 2012.

4. Pada komponen evaluasi K3 didapatkan penilaian sebesar 93\% sehingga dikategorikan baik dan telah menerapkan evaluasi K3 sesuai dengan ketentuan PP No. 50 tahun 2012.

5. Pada komponen tindakan perbaikan K3 didapatkan penilaian sebesar $97 \%$ sehingga dikategorikan baik dan telah menerapkan tindakan perbaikan K3 sesuai dengan ketentuan PP No. 50 tahun 2012.

6. Dari tahun 2010 jumlah kecelakaan kerja sebesar 3/1.000.000 jam kerja, sedangkan pada tahun 2016 jumlah kecelakaan kerja hanya sebesar
1/1.000.000 jam kerja. Jumlah severity rate pada tahun 2010 sebesar 24/1.000.000 jam kerja, sedangkan pada tahun 2016 hanya sebesar 10/1.000.000 jam kerja.

\section{SARAN}

Saran yang dapat diberikan untuk meningkatkan manajemen K3 di perusahaan adalah perusahaan harus melaksanakan komitmen dan kebijakan secara maksimal. Hal ini ditujukan agar para pekerja lebih disiplin khususnya dalam menggunakan alat pelindung diri.

\section{DAFTAR PUSTAKA}

Sastrohadiwiryo, B.Siswanto. 2003. Manajemen Tenaga Kerja Indonesia: Pendekatan Administratif dan Operasional. Jakarta, PT Bumi Aksara.

Kementerian Tenaga Kerja dan Transmigrasi, 2012. Peraturan Pemerintah Nomor 50 Tahun 2012 Tentang Penerapan Sistem Manajemen Keselamatan dan Kesehatan Kerja.

Mathis, Robert L dan John $\mathrm{H}$ Jackson, 2002. Manajemen SDM. Jakarta, Salemba Empat.

OHSAS 18001: 2007. Sistem Manajemen Keselamatan dan Kesehatan Kerja, diakses tanggal 12 januari 2017.

PP No. 50 tahun 2012. Sistem Manajemen Keselamatan.

Rahmat, P, S, 2009. Penelitian kualitatif. Jurnal. Equilibrum, vol-5, no 9, JanuariJuni 2009 : 1-8.

Ramadhan, Achmad, 2012. Penerapan Sistem Manajemen Keselamatan dan Kesehatan Kerja (Smk3) (Studi Pada Proyek Pembangunan Jalan Rawa Buaya, Cengkareng). Depok, Universitas Indonesia : 3-5. 
Ramli, Soehatman, 2010. Sistem Manajemen Keselamatan dan Kesehatan Kerja OHSAS 18001. Jakarta, Dian Rakyat : 46-57.

Ramli, Soehatman, 2013. Smart Safety Panduan Penerapan SMK3 yang Efektif. Jakarta, Dian Rakyat : 243-244.

Sahab MS, Syukri, 1997. Manajemen Keselamatan dan Kesehatan Kerja. Jakarta, PT. Pustaka Binamana Pressindo.

Silaban, Gery, Soebijanto, dkk, 2009. Kinerja Penerapan Sistem Manajemen Keselamatan Dan Kesehatan Kerja Perusahaan Peserta Program Jaminan Kecelakaan Kerja Pada PT Jamsostek Cabang Medan. Yogyakarta, Universitas Gajah Mada. 